\title{
Predictive Factors for the Efficacy of Voice Therapy for Pediatric Vocal Fold Nodule
}

\author{
Chang Bin Yun (D), Young-Mo Kim (D), Jeong-Seok Choi (D), and Ji Won Kim (iD) \\ Department of Otolaryngology-Head and Neck Surgery, Inha University College of Medicine, Incheon, Korea
}

소아 성대결절의 음성치료 효과에 미치는 예후 인자

윤창빈, 김영모, 최정석, 김지원

인하대학교 의과대학 이비인후과학교실

Background and Objectives Voice therapy (VT) is considered to be the gold standard of treatment of vocal fold nodule in children. This study was designed to analyze the success rate of pediatric VT and investigate the predictive factors for good response of periatic VT for vocal fold nodule.

Materials and Method This was a retrospective cohort study of 23 patients under 18 years old who were diagnosed with vocal fold nodule and received pediatric VT. We divided the patients into responding and non-responding groups. We analyzed clinical and voice parameters related to the voice results.

Results Twelve patients showed improved findings after VT. By univariate analysis, female patients (85.7\%) and adolescence children (100\%) showed a good response to VT. In multivariate analysis, female sex $(p<0.05)$ and adolescence children $(p<0.05)$ were significantly related to a successful voice response. Proton pump inhibitor or antihistamine, mucolytics treatment and pre-VT voice parameters did not significantly influence voice outcomes.

Conclusion Pediatric VT is more effective in female and adolescence children.

Keywords Pediatric; Vocal fold nodule; Voice therapy; Predicting factors.

\section{서 론}

성대결절은 지속적인 음성 오남용으로 인해 생길 수 있으며, 조직학적으로 양측 성대 간의 과도한 마찰로 인해 기저막과 상피 기저세포의 분리가 일어나 국소적인 세포액 침 착이 일어나게 되고, 치유과정에서 기저막의 생성이 이루어지기 전에 다시 성대가 손상 을 받게 되면, 반흔 조직으로 대치되어 발생한다[1-3]. 성대결절은 소아 음성장애 원인의 $35 \%-78 \%$ 를 차지하는 것으로 알려져 있으며, 남녀비가 약 2:1로 남아에서 호발하고 연 령대는 3-10세가 많다고 보고되고 있다[4]. 또한 성격이 좀더 외향적인 경우, 형제 자매 가 있는 소아의 경우에 좀더 호발하는 것으로 보고되고 있다[5-7].

소아의 음성 문제는 또래 집단에서 부정적인 평가를 받을 수 있으며 소아의 자존감과 자아 형성에 영향을 줄 수 있기 때문에 소아 성대 결절의 치료는 매우 중요하지만[8], 성
Received August 13, 2021

Revised September 28, 2021

Accepted October 12, 2021

\section{Corresponding Author}

Ji Won Kim, MD, PhD

Department of Otorhinolaryngology-

Head and Neck Surgery,

Inha University School of Medicine,

27 Inhang-ro, Jung-gu,

Incheon 22332, Korea

Tel +82-32-890-2817

Fax+82-32-890-3580

E-mail hopefuljw@gmail.com

\section{ORCID iDs}

Chang Bin Yun (D)

https://orcid.org/0000-0003-2963-6777

Young-Mo Kim (D)

https://orcid.org/0000-0003-0016-0904

Jeong-Seok Choi (D)

https://orcid.org/0000-0001-9669-2141

Ji Won Kim (iD)

https://orcid.org/0000-0003-1587-9671

This is an Open Access article distributed under the terms of the Creative Commons Attribution Non-Commercial License (https://creativecommons.org/ licenses/by-nc/4.0) which permits unrestricted non-commercial use, distribution, and reproduction in any medium, provided the original work is properly cited. 
대 결절의 적절한 치료 방법에 대해서는 여전히 논란이 있다 [9,10]. 수술적 치료와 음성치료(voice therapy, VT) 중 대부 분의 이비인후과 의사들은 음성치료를 권장하지만[11], 환자 의 연령이 낮을수록 음성 남용 습관의 교정이 힘들고, 소아 음 성치료의 낮은 순응도와 음성치료에 대한 부모의 낮은 인식 이 소아 성대결절의 음성치료를 더욱더 어렵게 만든다.

저자들은 소아 성대결절 환자에서 음성치료의 예후 인자 및 임상적 특성을 파악하여 향후 치료에 도움을 얻고자 본 연구를 시행하였다.

\section{대상 및 방법}

2014년 1월부터 2017년 12월까지 본원에서 성대 결절로 진 단 받은 소아 환자 30 명을 대상으로 의무기록을 후향적으로 검토하였다. 본 연구는 기관 연구윤리 심의위원회의 허가를 받 고 시행하였다(IRB No. 2021-12-029). 그 중 1명은 수술적 치료를 시행 받았으며, 6명은 추적 소실(follow up loss)되어 제외하였고, 총 23명의 소아 환자가 연구에 포함되었다. 예후 인자로 성별, 연령, 복용 약물 여부(프로톤펌프억제제, 안티 히스타민, 점액용해제) 등을 조사하였다. 처음 내원시 후두경 (laryngoscopy)검사를 통해 성대결절을 진단하였고, 이후 Computerized Speech Lab (CSL, Model 4500; Kay-Pentax, Montvale, NJ, USA)의 다차원 음성측정기를 음성 분석 에 사용하였다. 음성 평가는 조용한 방에서 시행되었고, 마이 크는 환자의 입에서 $3 \mathrm{~cm}$ 떨어진 곳에 배치하여 검사를 진행 하였다. CSL 검사를 통해 jitter, shimmer, noise-harmony ratio (NHR), maximum phonation time (MPT), mean flow rate (MFR), closed quotient (CQ)를 측정하였다. 또한 1급 언 어 재활사(speech-language pathologist)는 환자의 목소리에 대한 청지각적 평가를 Grade-Roughness-Breathiness-Asthenia-Strain (GRBAS) scale을 통해 수치화 하였다. 음성치 료는 직접 및 간접(direct and indirect methods) 음성치료 방 법을 사용하였고, 1 주일에 1 회 치료를 계획하였고, 환자에 따 라 1회부터 8회 시행한 경우로 다양했으며, 평균 총 4회 시행하 였다. 보호자 동행으로 계획하였으며, 세션당 시간은 약 40 분 정도 치료가 진행되었다. 직접 음성치료는 후두 마사지, 하품한숨 접근법, 공명 훈련, 다양한 크기의 빨대를 사용하는 반 폐색성 발성 훈련(semi-occluded vocal tract training) 등을 포함 하였고, 간접 치료에는 별도의 배부자료를 사용하지는 않 았고, 내원하여 음성치료를 시행할 때마다 간접치료로서 환자 의 음성 문제 인식 교정과 수분 섭취 및 음성 남용 교정 등의 음성 위생 교육을 포함하였다. 음성치료를 시작한지 평균 3개 월 이후 후두경 검사를 통해 성대 결절의 크기를 비교하였고,
결절의 크기가 작아지거나 소실된 경우 음성치료의 효과가 있 는 것으로 판정하였다(Fig. 1).

분석은 SPSS 22 (IBM Corp., Armonk, NY, USA)를 사용 하였고, 통계학적으로 유의한 것으로 판단하는 기준은 $\mathrm{p}<0.05$ 인 경우로 하였다. 환자의 통계적 유의성 검증을 위해 성별, 약물 복용 유무와 같은 범주형 변수는 Fisher's exact tests 를 시행하였으며 나이, 치료 횟수, 음성 분석 결과와 같은 연 속 변수는 Mann-Whitney U test를 시행하였다.

\section{결 과}

연구에 포함된 23명의 소아 성대결절 환아 중 음성치료에 반응을 보인 소아 환자는 총 12 명(52.2\%)이었고, 11 명(47.8\%) 은 결절의 사이즈가 변화가 없거나 더욱 증가하였다. 음성치 료에 좋은 반응을 보인 군과 아닌 군을 비교해보면, 여자 환 자의 비율이 음성치료에 반응을 보이지 않았던 군보다 음성 치료에 좋은 반응을 보인 군에서 통계적으로 유의하게 높았 고(9.1\% vs. $50.0 \%, \mathrm{p}=0.033)$, 연령별로 학동 전기(3-5세), 학 령기(6-11세), 청소년기(12-18세)로 나누어 보았을 때 음성치 료에 반응을 보인 군 중 청소년기의 비율이 통계적으로 유의 하게 높았다 $(\mathrm{p}=0.016)$. 음성치료의 빈도수나 약물치료 (proton pump inhibitor, antihistamine, mucolytics)의 유무에 따라서는 양 군이 통계학적으로 유의미한 차이를 보이지 않 았다(Table 1).

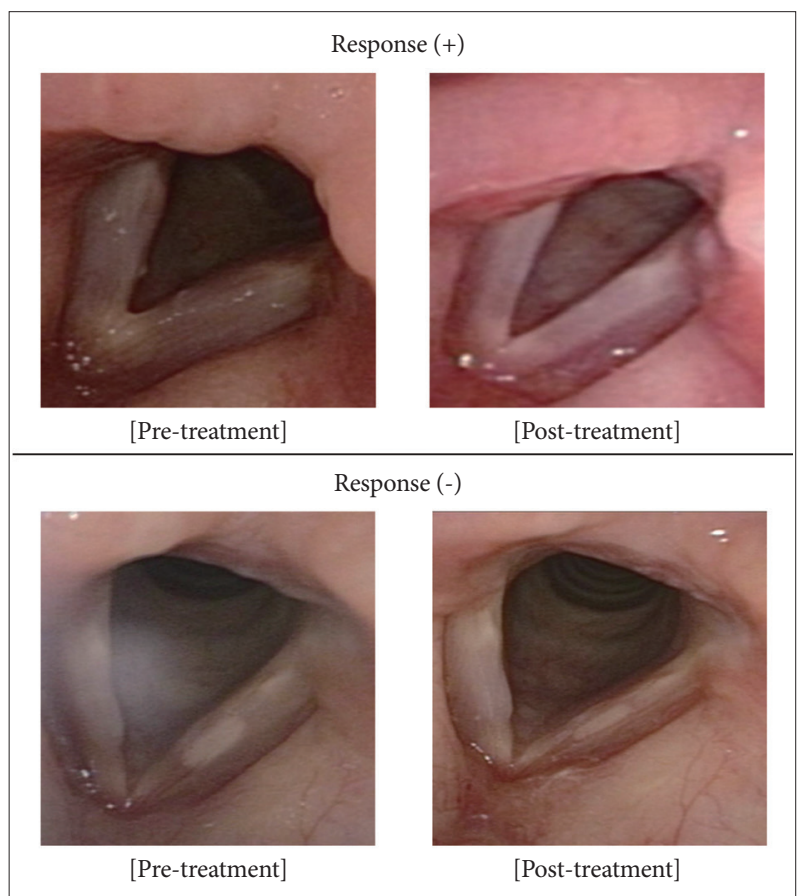

Fig. 1. Comparison of vocal cords before and after voice therapy in the responder and non-responder groups. 
Table 1. Patient demographics and clinical characteristics $(n=23)$

\begin{tabular}{lccc}
\multicolumn{1}{c}{ Variable } & $\begin{array}{c}\text { Response } \\
(-)\end{array}$ & $\begin{array}{c}\text { Response } \\
(+)\end{array}$ & p \\
Total & $11(42.8)$ & $12(52.2)$ & \\
$\quad$ Sex, female & $1(9.1)$ & $6(50.0)$ & $0.033^{*}$ \\
Age (yr) & $8.36 \pm 5.06$ & $9.75 \pm 5.40$ & $0.332^{\dagger}$ \\
$\quad$ Preschool-age (3-5) & $2(18.2)$ & $3(25.0)$ & - \\
School-age (6-11) & $9(81.8)$ & $4(33.3)$ & - \\
$\quad$ Adolescence $(\geq 12)$ & $0(0)$ & $5(41.7)$ & $0.016^{*}$ \\
Frequency of VT session & $3.27 \pm 1.95$ & $4.33 \pm 2.31$ & $0.250^{\dagger}$ \\
Medication & & & \\
$\quad$ Proton pump inhibitor & $7(63.6)$ & $10(83.3)$ & $0.283^{*}$ \\
$\quad$ Antihistamine & $4(36.4)$ & $2(16.7)$ & $0.283^{*}$ \\
Mucolytics & $4(36.4)$ & $3(25.0)$ & $0.554^{*}$ \\
\hline
\end{tabular}

Data are presented as n (\%) or mean \pm standard deviation. *Pearson's chi-square test or Fisher's exact test were used in statistical analyses; ${ }^{\dagger}$ Mann-Whitney $\mathrm{U}$ test were used in statistical analyses. VT, voice therapy

Table 2. Comparison of each voice parameter between groups

$\begin{array}{lccc} & \begin{array}{c}\text { Response } \\ (-)\end{array} & \begin{array}{c}\text { Response } \\ (+)\end{array} & \mathrm{p}^{*} \\ \text { Aerodynamic study } & & & \\ \text { MPT (sec) } & 6.77 \pm 3.16 & 7.37 \pm 4.06 & 0.705 \\ \text { MFR (mL/sec) } & 154.55 \pm 88.92 & 156.40 \pm 109.57 & 0.966 \\ \text { Acoustic analysis } & & & \\ \text { Jitter (\%) } & 1.54 \pm 1.35 & 1.87 \pm 1.53 & 0.082 \\ \text { Shimmer (\%) } & 6.21 \pm 6.80 & 5.34 \pm 3.11 & 0.118 \\ \text { NHR } & 0.20 \pm 0.08 & 0.17 \pm 0.07 & 0.533 \\ \text { Electroglottography } & & & \\ \text { Closed quotient } & 47.10 \pm 5.46 & 49.36 \pm 7.05 & 0.442 \\ \text { Perceptional analysis } & & & \\ \text { GRBAS item scores } & & & \\ \text { G } & 0.89 \pm 0.64 & 1.23 \pm 0.62 & 0.559 \\ \text { R } & 1.87 \pm 0.69 & 1.75 \pm 0.62 & 0.662 \\ \text { B } & 1.25 \pm 0.46 & 1.00 \pm 0.54 & 0.334 \\ \text { A } & 0.58 \pm 0.40 & 0.22 \pm 0.46 & 0.562 \\ \text { S } & 0.29 \pm 0.42 & 0.19 \pm 0.62 & 0.359\end{array}$

Data are presented as mean \pm standard deviation. *Mann-Whitney $\mathrm{U}$ test was used in statistical analyses. MPT, maximum phonation time; MFR, mean flow rate; Psub, peak subglottic pressure; VE, vocal efficiency; NHR, noise-harmony ratio; GRBAS, grade-roughness-breathiness-asthenicity-strain scale

음성치료 전에 시행한 음성평가(CSL 및 GRBAS scale)의 항목 중 음성치료의 효과에 영향을 미치는 인자가 있는지 확 인해 보았을 때, 유의미한 인자는 없었다. CSL 평가 중 MPT, MFR, jitter, shimmer, NHR, CQ 항목을 비교해 보았고, jitter 항목에서 효과를 본 군에서 1.87 로 효과를 보지 못한 군보다 약간 크게 측정되었으나 이는 통계적으로 의미있는 차이를 보이지 않았다 $(\mathrm{p}=0.082)$. GRBAS scale의 항목에서
도 음성치료에 효과가 있었던 군과 아닌 군 간에 통계적으로 유의한 차이를 보이지 않았다(Table 2).

\section{고 찰}

소아 성대결절은 연령이 낮을수록 절대 음성 안정에 대한 이해도가 낮고, 음성 남용 습관의 교정이 힘들며, 음성치료 중 습득한 방법을 일상생활에 일반화하여 장기적으로 관리 하기 어렵기 때문에 궁극적인 치료도 어렵고 재발도 잦다. 따 라서, 많은 임상의들이 치료에 어려움을 겪고 있으며, 일부 의사들은 환자와 보호자에게 치료를 권하기를 주저하기도 한다[12].

이러한 이유로 소아 성대결절 음성치료의 효과를 평가한 연구도 많지 않다. 총 4건의 연구에서 경과 관찰 또는 음성치 료의 효과를 비교하였다[9,12-14]. 1999년에 소아(2-18세) 성 대결절 환자 169 명을 대상으로 한 연구에서는 음성치료를 받 은 환자군의 $52 \%$ 에서, 음성 위생 교육을 받은 환자군의 $16 \%$ 에서 음성 호전을 보였다[9]. 본 연구에서 음성치료 효과를 보 인 군이 $52 \%$ 로 확인되어 비슷한 정도의 치료율을 보였다고 할 수 있다. 2018년에는 소아 성대결절 환자 114명을 대상으 로 음성치료법 중 직접 치료 접근법과 간접 치료 접근법을 비 교하는 무작위 대조군 연구가 시행되었다[13]. 직접 치료를 받 은 환자군의 치료 전후 평균 음성 관련 삶의 질 지표 점수 변 화는 19.2점이었고, 간접 치료를 받은 환자군의 경우 평균 14.2 점의 결과를 보였다. 2014년에는 3.8-20.6세 사이의 소아 환자 67 명을 대상으로 시간 경과에 성대결절 크기의 변화에 대한 연구도 시행 되었는데, 경과 관찰만 하거나 습관 교정을 교육 받은 환자군과 비교하여 음성치료를 받은 환자군에서 통계적 으로 유의하게 더 큰 호전을 보였다[14]. 국내에서는 2018년에 소아(3-11세) 성대결절 환자 13명을 대상으로 한 연구에서 모 든 환자에서 음성치료 후 모든 청지각적, 음향학적, 주관적 지 표에서 치료 전후 통계학적으로 유의한 호전을 보였다[12]. 본 연구에서는 치료 전후 음성치료의 효과를 비교하기 보다는 음성치료의 효과가 더 좋은 군의 치료전 임상적 특징을 살펴 보았으며, 음성치료 전 청지각적, 음향학적 지표는 예후에 영 향을 미치지 않았다.

음성치료는 환자의 순응도가 중요한 인자이다. 나이가 어 릴수록 음성장애에 대한 인지가 떨어져 치료에 대한 순응도 가 떨어지게 된다. 학령기가 되고, 청소년기가 되면 음성의 이 상에 따른 자존감이 떨어질 수 있고, 자아 형성에 영향을 줄 수 있는 가능성이 커지게 된다[8]. 연령이 증가함에 따라 음성 의 이상에 대해 심각성을 가지게 됨으로써 음성치료에 순응 도가 향상된다. 본 연구에서 청소년기 환자군 5 명 모두 음성 
치료에 효과를 보았던 것은 순응도 및 환자의 의지력의 요인 이 크게 작용했을 것으로 사료된다. 연령의 요소와 함께 의미 있는 차이를 보였던 인자로 성별의 차이가 있다. 여자 환자의 경우 7명중 6명(85.7\%), 남자 환자의 경우 16명중 6명(37.5\%) 만이 효과를 보았다. 이는 성인 성대용종 음성치료의 효과를 비교한 연구[15]의 결과와 일치하는 경향을 보였다. 역으로 보 면 어린 남아에서는 음성치료의 효과는 미미할 것으로 예상 할 수 있다. 한편, 음성치료의 빈도에서는 양군의 차이를 보 이지 않았는데, 소아 성대결절은 음성치료를 한 횟수가 중요 하기보다는 환자의 순응도에 따라 음성치료를 얼마나 일상 생활에 잘 접목하는지가 더 중요한 것으로 사료된다. 또한, 성 인의 경우 음성치료의 방법으로 프로톤펌프억제제 등의 약 물치료를 병행하기도 하는데, 약물치료가 음성치료의 결과에 유의한 영향을 미치지 않는다는 보고가 많다[16,17]. 본 연구 에서도 약물치료에 따른 음성치료 효과 차이는 없어 소아 음 성결절에서도 비슷한 경향을 보이는 것으로 여겨진다.

음성치료 전 청지각적 음향학적 평가 지표상에서 초기 음 성의 상태에 따른 비교에서도 유의한 치료 예측인자를 찾을 수가 없었다. 이는 초기 음성의 좋고 나쁨에 따라 음성치료 의 효과를 예측할 수 없다는 것을 의미한다.

연구의 한계점으로는 연령에 따른 환자의 표본수가 적다는 점이 있을 수 있겠고, 음성치료의 반응 유무를 판단함에 있 어 후두경 검사상 결절의 크기로만 판단하였기에 환자의 주 관적 반응을 고려하지 않았다는 한계가 있다. 그리고 환아의 GRBAS score의 전반적 평균이 낮아서 score에 의미있는 차 이가 보이지 않고 중재의 효과가 덜 나타났을 가능성이 있다. 또한 소아 성대결절에 영향을 줄 수 있다고 알려져 있는 요인 인 환아의 성격 및 형제 자매의 유무, 스포츠 활동을 하는지 등에 대해서 확인하지 못하였다는 점에서 연구의 한계가 있 다. 또한 향후 음성치료 전후 주관적, 소아 음성 관련 삶의 질 지표(pediatric voice-related quality of life) 비교 및 청지각 적, 음향학적 결과를 비교하는 연구 등이 필요할 것으로 사료 된다. 또한 성대결절의 위치에 따른 음성치료 효과가 어떻게 다른지, 기저질환에 따라 음성치료 효과가 어떻게 달라질 수 있는지에 대해서 연구가 추가로 필요할 것으로 사료된다.

\section{결 론}

소아 성대결절의 음성치료의 좋은 예후 인자는 성별(여아) 과 나이(고령)이며, 치료 전 음향학적 청지각적 지표로는 음 성치료의 효과를 예측할 수 없다. 본 연구의 결과가 소아 성 대결절 음성치료 방침을 결정함에 있어 초석이 될 수 있을 것 이라 생각된다.
중심 단어: 소아; 성대결절; 음성치료; 예후인자.

Acknowledgments

This work was supported by Inha University Hospital Research Grant.

Conflicts of Interest

The authors have no financial conflicts of interest.

\section{Authors' Contribution}

Conceptualization: Ji Won Kim. Data curation: all authors. Formal analysis: Ji Won Kim. Investigation: all authors. Methodology: Ji Won Kim. Validation: Ji Won Kim. Visualization: Chang Bin Yun. Writing-original draft: Chang Bin Yun, Ji Won Kim. Writing-review \& editing: Chang Bin Yun, Ji Won Kim. Approval of final manuscript: all authors.

\section{REFERENCES}

1. Akif Kiliç M, Okur E, Yildirim I, Güzelsoy S. The prevalence of vocal fold nodules in school age children. Int J Pediatr Otorhinolaryngol 2004;68(4):409-12.

2. Morrison M, Rammage L, Nichol H, Pullan B, May P, Salkeld L. Pediatric voice disorders: special considerations. In: Morrison M, Rammage L, Nichol H, Pullan B, May P, Salkeld L, editors. The Management of Voice Disorders. Boston: Springer;1994. p.120-40.

3. Kim HT, Cho SH, Park HJ, You WJ, Kim MS. Histopathological characteristics in benign lesions of the vocal folds by expression of collagen type IV in the basement membrane zone. Korean J Otorhinolaryngol-Head Neck Surg 1996;39(9):1477-84.

4. Dobres R, Lee L, Stemple JC, Kummer AW, Kretschmer LW. Description of laryngeal pathologies in children evaluated by otolaryngologists. J Speech Hear Disord 1990;55(3):526-32.

5. Verduyckt I, Rhéault C, Remacle M, Morsomme D. Personality traits of children with vocal fold nodules. J Voice 2019;33(5):801.e1-6.

6. Tuzuner A, Demirci S, Oguz H, Ozcan KM. Pediatric vocal fold nodule etiology: What are its usual causes in children? J Voice 2017;31(4): 506.e19-23.

7. Lee JM, Roy N, Dietrich M. Personality, psychological factors, and behavioral tendencies in children with vocal nodules: A systematic review. J Voice 2019;33(6):945.e1-18.

8. Hooper CR. Treatment of voice disorders in children. Lang Speech Hear Serv Sch 2004;35(4):320-6.

9. Mori K. Vocal fold nodules in children: Preferable therapy. Int J Pediatr Otorhinolaryngol 1999;49 Suppl 1:S303-6.

10. Shah RK, Woodnorth GH, Glynn A, Nuss RC. Pediatric vocal nodules: Correlation with perceptual voice analysis. Int J Pediatr Otorhinolaryngol 2005;69(7):903-9.

11. Allen MS, Pettit JM, Sherblom JC. Management of vocal nodules: A regional survey of otolaryngologists and speech-language pathologists. J Speech Hear Res 1991;34(2):229-35.

12. So YK. Efficacy of voice therapy for children with vocal nodules. J Clinical Otolaryngol 2018;29(2):229-34.

13. Hartnick C, Ballif C, De Guzman V, Sataloff R, Campisi P, Kerschner $\mathrm{J}$, et al. Indirect vs direct voice therapy for children with vocal nodules: a randomized clinical trial. JAMA Otolaryngol Head Neck Surg 2018;144(2):156-63.

14. Nardone HC, Recko T, Huang L, Nuss RC. A retrospective review of the progression of pediatric vocal fold nodules. JAMA Otolaryngol Head Neck Surg 2014;140(3):233-6.

15. Lee YS, Lee DH, Jeong GE, Kim JW, Roh JL, Choi SH, et al. Treatment efficacy of voice therapy for vocal fold polyps and factors predictive of its efficacy. J Voice 2017;31(1):120.e9-13. 
16. Choi N, Kim DG, Lee GJ. Analysis for risk factors and effect of vocal hygiene education in patients of vocal polyp. J Korean Soc Laryngol Phoniatr Logop 2021;32(1):24-8.
17. Kuhn J, Toohill RJ, Ulualp SO, Kulpa J, Hofmann C, Arndorfer R, et al. Pharyngeal acid reflux events in patients with vocal cord nodules. Laryngoscope 1998;108(8 Pt 1):1146-9. 